\title{
Analisis Matematika Pada Pembuatan Rumah Panggung Toraja
}

\author{
Syafruddin Side $^{1,}$, dan Sukarna ${ }^{1,}$, dan Jusriadi ${ }^{1, a)}$ \\ ${ }^{1}$ Jurusan Matematika FMIPA Universitas Negeri Makassar, 90224 \\ a)jusriadisamsuddin19@gmail.com
}

\begin{abstract}
Abstrak. Geometri merupakan cabang ilmu yang mempelajari tentang hubungan antara titik-titik, garisgaris, dan bidang-bidang serta bangun datar dan bangun ruang. Dalam penerapan matematika geometri sangat membantu dalam kehidupan sehari-hari. Sebagai contoh penentuan tinggi menara dengan menggunakan bantuan cahaya matahari dimana dalam penentuannya bisa menggunakan sistem perbandingan. Kemudian menentukan jarak atau lebar sungai tanpa mengukur secara manual yaitu dengan menggunakan titik bantuan dan garis yang sebangun. Penelitian ini bertujuan mengetahui bagaimana hasil penerapan matematika dalam pembuatan rumah panggung Toraja. Dalam proses analisis dilakukan observasi dan wawancara serta dokumentasi untuk melihat proses pembuatan rumah panggung Toraja. Berdasarkan hasil analisis data yang diperoleh, ditemukan pola barisan pada tiang atau balok di setiap tipe rumah. Kemudian metode penggunaan garis sejajar, perpanjangan garis dan kesebangunan pada atap rumah. aplikasi matematika dapat diterapkan pada rumah panggung Toraja menggunakan persamaan dan fungsi parabola pada penentuan lengkungan atap rumah.
\end{abstract}

Kata kunci: Geometri, Rumah panggung Toraja, Analisis, Persamaan

\begin{abstract}
Geometry is branch of science that learning about the relationship between points, lines, sides , plane figure and solid figure. The application of geometry mathematics is very helpful in daily life. For example, the determination of tower height by using sunlight where in its determination can use the comparison system. Then, determine the distance or width of the river without measuring it manually, that is by using the help points and lines that are congruent. The aim of this research is finding out how the results of the application of mathematics in building Toraja Traditional house. The analysis process is done by observation, interview and documentation to see the process of building Toraja Traditional house. Based on the results of data analysis that is obtained, it was find the sequences pattern on the poles or beams in each type of house. Then the method of using parallel lines, lines extension and similarity on the roof of the house. Mathematics application can be applied in Toraja Traditional house by using parabolic equations and parabolic functions in determining the curvature of house roof.
\end{abstract}

Keyword: Geometry,Toraja Traditional House, Analysis, Equation

\section{PENDAHULAN}

Matematika adalah ilmu tentang bilangan-bilangan, hubungan antar bilangan dan prosedur operasional yang digunakan dalam penyelesaian masalah bilangan. Dalam perkembangannya bilangan ini diaplikasikan ke bidang ilmu-ilmu lain sesuai penggunaannya. Menurut James (1976), matematika diartikan sebagai ilmu logika mengenai bentuk, susunan, besaran, dan konsep-konsep yang saling berhubungan satu sama lainnya dengan jumlah yang terbagi ke dalam tiga bidang yaitu aljabar, analisis, dan geometri. 
Penerapan matematika khususnya geometri dalam kehidupan sehari-hari sangat banyak sekali. Menurut Ratnasari (2016) bahwa geometri adalah cabang ilmu matematika yang mempelajari tentang hubungan antara titik-titik, garis-garis, bidang-bidang serta bangun datar dan bangun ruang. Geometri merupakan salah satu sistem matematika, dimana didalamnya memiliki banyak konsep pangkal, mulai unsur primitive atau unsur tak terdefinisi, antaranya yaitu titik, garis kurva ataupun bidang dan juga terdapat relasi-relasi pangkal yang tidak terdefenisikan, misalkan: melalui, terletak, pada, memotong, dan antara. Dari unsur-unsur yang tak terdefenisikan itu kemudian membangun unsur-unsur yang didefinikan dan selanjutnya ke aksioma atau postulat dan akhirnya pada teorema atau dalil.(Anisa, 2017)

Dalam penerapannya geometri sangat berguna sekali dalam ilmu arsitektur. Dimana proses perancangannya sederhana (hanya merupakan susunan komposisi dan proporsi) sampai arsitektur yang proses perancangannya sangat kompleks (dengan memasukkan parameter-parameter kebutuhan computer manusia, bahkan parameter waktu) semuanya memiliki unsur-unsur geometri yang harus dikaji dan dipelajari. Ide apa pun yang ada di dalam kepala kita sebagai awal ide perancangan, bisa kita kaitkan ke geometri untuk lebih memperkaya, bukan hanya bentuk, melainkan juga sirkulasi dan esensi yang ada dalam rancangan kita. Oleh karena itu, dalam merancang sebuah arsitektur tidak bisa lari dari geometri. Geometri dalam arsitektur memiliki sifat mengikat, karena sebagai perancang tidak bisa tidak mempertimbangkan geometri.(Jannah, 2014)

Peranan geometri yang bisa digunakan yaitu pada pembuatan rumah. Menurut Roro (2015), rumah merupakan salah satu kebutuhan dasar manusia. Dalam perkembanganya, rumah sebagai tempat berlindung dan memiliki beragam bentuk, ukuran dan desain. Salah satunya adalah rumah panggung yang mempunyai sejumlah kelebihan, di antaranya sebagai anti banjir, aman terhadap binatang buas, halaman lebih luas, tahan gempa, kesan tradisional yang kuat, bentuknya unik, dan interior lebih sejuk.(Arafuru, 2014)

Salah satu peranan geometri pada rumah panggung yaitu rumah adat Toraja atau biasa disebut Tongkonan. Dimana menurut Maspamuji (2016), Tongkonan adalah rumah tradisional Toraja yang berdiri di atas tumpukan kayu dan dihiasi dengan ukiran berwarna merah, hitam, dan kuning. Kata "tongkonan" berasal dari bahasa Toraja tongkon (duduk). Dalam Tandililing (2015), unsur budaya yang paling mendominasi adalah ukiran-ukiran yang unik dan menarik. Jika dilihat secara seksama ukiran-ukiran tersebut semuannya dituangkan dalam bangun-bangun geometri. Olehnya, dapat disimpulkan bahwa secara tidak sadar sejak dulu suku Toraja sudah mengenal matematika khususnya geometri bahkan telah dipraktekkan dalam kehidupan sehari-hari. Hanya saja mereka tidak mengenal nama-nama bangun tersebut. Hal inilah yang disebut dengan menganalisis unsur budaya suatu masyarakat menurut Spradley (2007). Penelitian ini mengarah kepada atnomatika geometri dimana atnomatika merupakan suatu studi tentang matematika dalam masyarakat. (Orey, 2000)

Selain itu, rumah adat toraja identik dengan lengkungan yang terletak diatap rumah adat toraja. Atap rumah adat toraja pun menjadi ciri khas tersendiri bagi rumah adat tersebut. Diluar dari filosofi rumah adat Toraja, lengkungan, ukiran dan bahan utama yang terbuat dari kayu dan bambu menjadi hal yang menarik untuk didalami lebih lanjut.

Penelitian ini berfokus pada analisis peran matematika terhadap pembuatan rumah panggung Toraja dengan tujuan untuk mengetahui hasil dan peran matermatika dalam pembuatan rumah panggung Toraja agar nantinya penelitian ini bisa memberikan gambaran tentang manfaat matematika dalam dunia sosial khusus pada rumah adat Toraja.

\section{METODE PENELITIAN}

Penelitian ini adalah penelitian kualitatif deskriptif yang bertujuan untuk mendeskripsikan hasil analisis dan penerapan matematika dalam pembuatan rumah panggung Toraja atau Tongkonan. 
Metode pengumpulan data yang digunakan adalah dokumentasi, observasi dan wawancara. Data yang dihasilkan adalah gambar fotograf dari rumah adat Toraja, hasil observasi, dan trangskrip wawancara. Data gambar digunakan untuk menganalisis matematika pada pembuatan rumah panggung Toraja. Hasil observasi digunakan sebagai alat pendukung dalam penelitian. Observasi dilakukan di dusun Poton, desa Madandang, kecamatan Rante Tayo, kabupaten Tanah Toraja. Transkrip wawancara digunakan sebagai informasi untuk pemperjelas apa yang ada digambar. Wawancara dilakukan dengan narasumber yaitu kepala suku.

\section{HASIL PENELITIAN}

Terdapat 6 hasil analisis matematika yang diperoleh dan sebuah penerapan matematika yang dapat digunakan dalam pembuatan rumah panggung Toraja.

\section{Hasil Analisis Matematika dalam Pembuatan Rumah Panggung Toraja}

1. Barisan geometri pada jumlah setiap balok atau benteng rumah.

Pada bagian kaki rumah terdapat banyak balok yang menyangga badan rumah, dimana balok tersebut berfungsi untuk menopang badan rumah yang berada di atasnya. Balok atau benteng rumah terbagi atas 3 jenis balok yaitu balok penyangga atau balok utama, balok penyangga atap, dan balok penyangga badan rumah. Berdasarkan hasil wawancara dengan narasumber yaitu kepala suka sekaligus tukang pembuat rumah panggung mengatakan:

"jumlah benteng atau balok badan rumah rata-rata 32 buah dan bisa saja akan berubah disetiap ukuran yang berbeda dan kondisi yang lain misalkan persediaan balok yang pas-pasan dan faktor lain. Namun yang dipastikan setiap ukuran rumah baik yang kecil sampai yang besar selalu sama jumlah balok atau benteng utama yaitu 2 dan balok penyangga atap rumah yaitu 8 "

Berdasarkan wawancara diatas, terdapat balok penyangga utama dan penyangga atap selalu berjumlah sama pada setiap ukuran rumah yaitu 2 dan 8 namun untuk balok badan rumah bisa saja berubah di setiap ukuran rumahya.

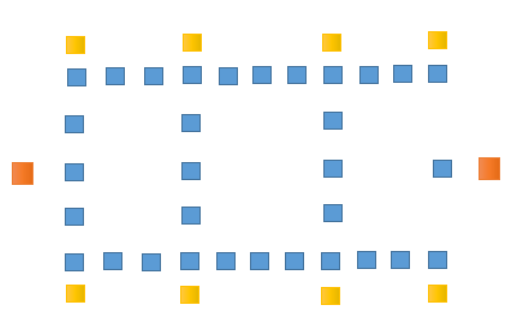

a)

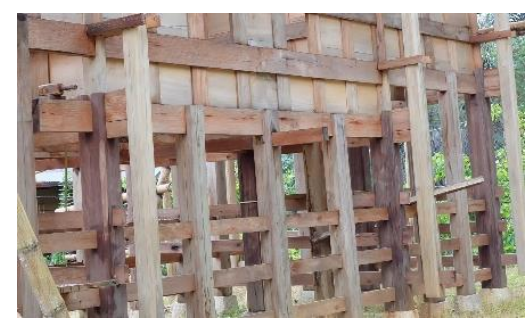

(b)

GAMBAR 1. (a) letak balok atau benteng rumah ukuran 3 meter x 7 meter. (b) gambar rumah bagian dasar atau kaki.

Ket : $\square$ Jumlah balok penyangga atau balok utama $=2$

$\square$ Jumlah balok penyangga atap $=8$

$\square$ Jumlah balok badan rumah $=32$

Dari Gambar 1 (a) terlihat jumlah balok utama atau penyangga yang berwarna orange sebanyak 2 balok, jumlah balok penyangga atap berwarna kuning sebanyak 8 balok, dan jumlah balok badan rumah berwarna biru sebanyak 32 balok. Jika jumlah semua balok ini disusun mulai dari yang jumlahnya sedikit sampai yang banyak maka terbentuk barisan 
geometri dengan rasio 4 dimana suku pertama adalah 2, suku kedua adalah 8 dan suku ke tiga adalah 32

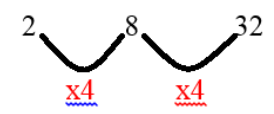

2. Penggunaan rumus pada penentuan panjang rumah.

Dari hasil wawancara dengan narasumber mengatakan bahwa:

"penentuan panjang rumah sebenarnya bisa ditentukan ketika sudah menentukan lebar rumah. Jadi caranya adalah misalkan lebarnya itu 3 meter maka panjangnya adalah lebar dikali 2 kemudian ditambah 1 sehingga panjangnya adalah 7 meter “

Berdasarkan hasil wawancara, penentuan panjang rumah dapat ditentukan dengan cara mengalikan lebar rumah dengan 2 kemudian ditambah dengan 1 , jika diubah dalam bentuk variabel, dimana panjang rumah adalah $p$ dan lebar rumah adalah $l$ maka:

$$
p=2 . l+1
$$

3. Penerapan berat dan tekanan dalam penyusunan rangka rumah

Dari hasil wawancara dengan narasumber mengatakan bahwa:

"rumah panggung Toraja dalam penyusunan rangka tidak terlalu menggunakan banyak paku melainkan mengandalkan berat dan tekanan. Oleh sebab itu atap rumah yang paling banyak komponen yang menyebabkan atap rumah lebih berat dibandingkan bagian yang lain"

Teori yang disampaikan narasumber adalah semakin besar tekanan maka ketahanan rumah semakin kuat. Dalam tahap pengerjaan diketahui ada tahap pengerjaan kaki rumah, tahap pengerjaan badan rumah, dan tahap atap. Ini dilakukan secara berturut yang dimulai dari kaki rumah, dilanjutkan dengan badan rumah dan terakhir bagian atap. Hal yang membuat badan rumah kuat karena adanya tekanan bagian atap rumah dan kaki rumah juga ditekan oleh badan rumah dan atap rumah. Untuk lebih jelasnya terlihat pada Gambar 2.

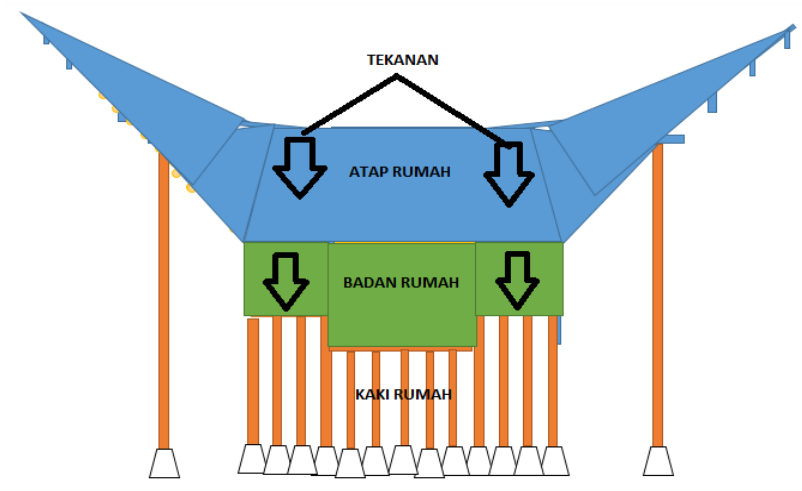

GAMBAR 2. Tampilan sisi kanan rumah.

4. Penggunaan sistem hubungan dua titik dan perpanjangan garis dalam mengukur kemiringan rangka depan atap dan belakang

Pada Gambar 3 bagian rangka atap rumah yang diubah dalam bentuk garis memperlihatkan bahwa adanya sebuah keterkaitan satu sama lain antara garis satu dengan garis yang lain. Untuk menentukan kemiringan atap bagian depan digunakan sistem 
hubungan dua titik dimana sistem ada dua titik yang sudah ditentungkan kemudian menarik garis dari titik satu ke titik yang lainnya, seperti pada Gambar 4.

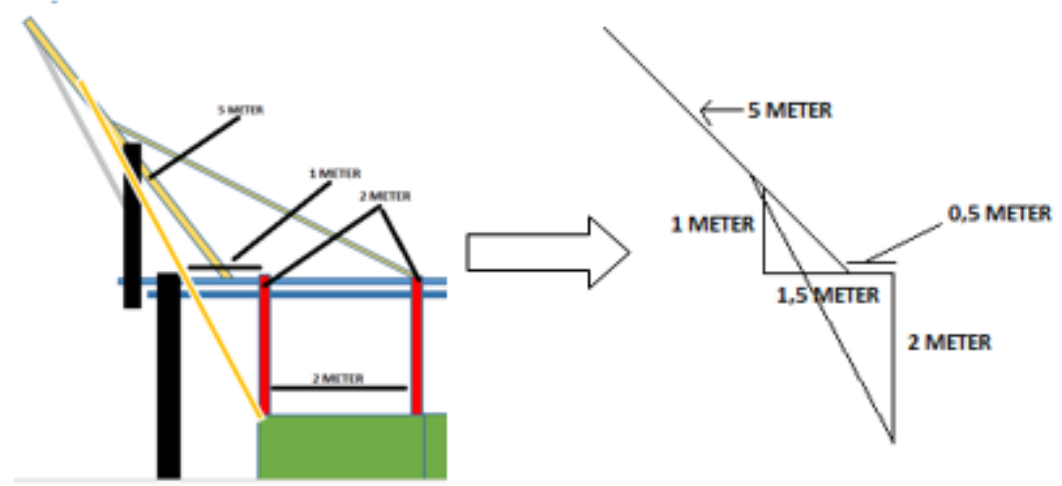

GAMBAR 3. Sketsa atap depan yang diubah dalam model garis.

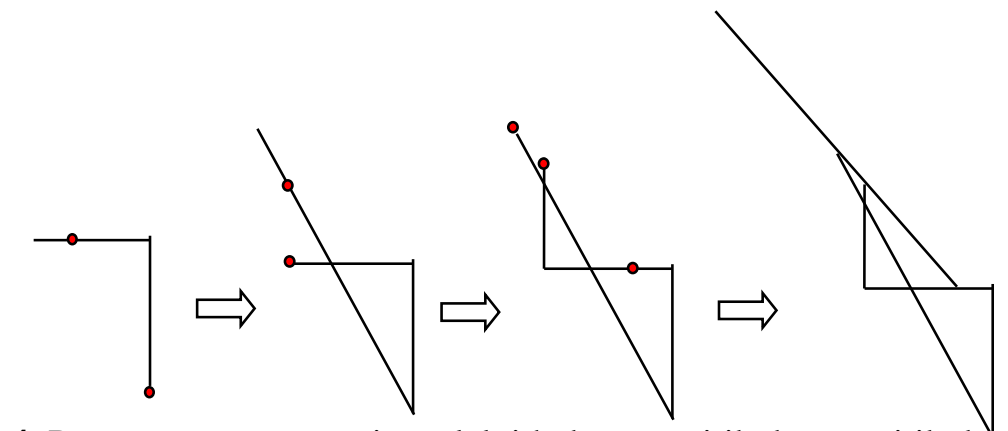

GAMBAR 4. Proses penentuan garis melalui hubungan titik dengan titik dah titik dengan garis

Diawali dengan dengan menentukan titik yang berada dikedua ruas garis dua kemudian dihubungan menjadi garis yang baru. Setelah itu menentukan kembali titik diruas garis yang terbentuk. Kemudian dihubungkan lagi sehingga membentuk ruas garis yang baru lagi sampai membentuk hubungan beberapa ruas garis yang menjadi rangka kemiringan atap rumah.

5. Lengkungan pada atap rumah

Lengkungan atap rumah terbentuk dari beberapa balok yang memiliki ukuran yang berbeda. Balok disusun vertikal dengan jarak tertentu dimulai dari bagian tengah rumah dengan balok ukuran terpendek sampai bagian depan rumah dengan balok ukuran tertinggi, terlihat pada Gambar 5.

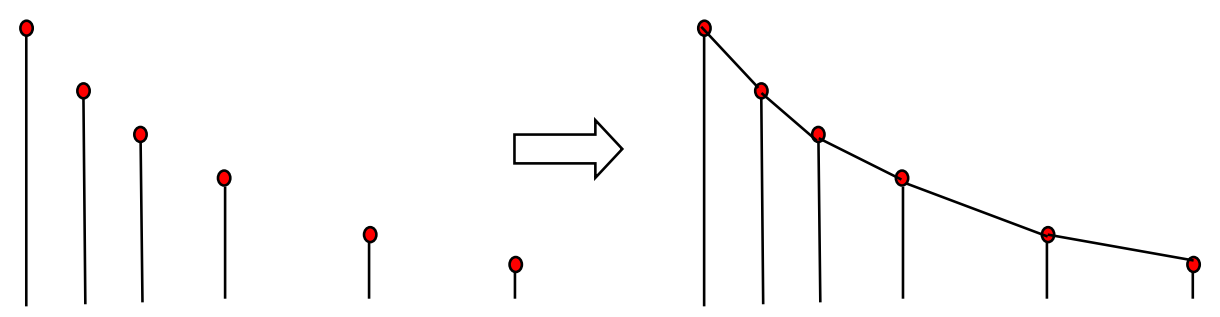

GAMBAR 5. Pembuatan lengkungan dengan menyusun balok dari tertinggi sampai terpendek dengan jarak tertentu

Dari balok yang disusun kemudian akan membentuk lengkungan ketika setiap ujung bagian atas balok dihubungkan. Kemudian untuk menyeimbangkan lengkungan rumah bagian 
depan dan bagian belakangan dilakakukan secara terbalik yaitu dari tengan rumah kebelakang. Agar lebih mudah, penempatan balok pembentuk lengkungan rumah bagian belakang bisa dilakukan dengan mengikuti jarak balok lengkungan rumah bagian depan dengan menggunakan sistem pencerminan, seperti pada Gambar 6.

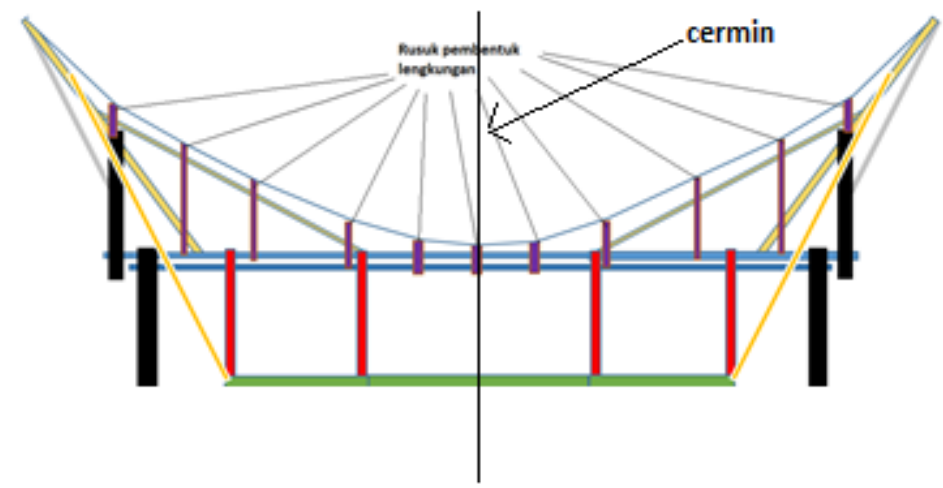

GAMBAR 6. Tampilan sketsa atap rumah

6. Kesebangunan dan kekongruengan pada bagian depan dan belakang rumah

Diketahui pada rumah panggung Toraja dibagian atap memiliki lengkungan dan tonjolan di depan dan dibelakang yang berbentuk seperti perahu. Jika rumah di bagi atas dua bagian maka akan terbentuk dua bangun yang sama dan kongruen terlihat seperti pada Gambar 7 .

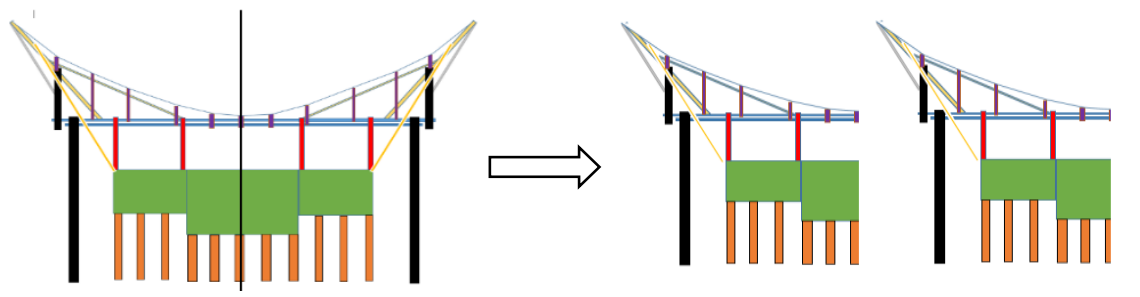

GAMBAR 7. Tampilan bagian depan rumah dan belakang rumah ketika dibagi dua

\section{Penerapan Matematika Aljabar dalam pembuatan rumah panggung Toraja}

Adapun penerapan matematika yang bisa digunakan dalam pembuatan rumah panggung Toraja adalah dibagian atap rumah yaitu lengkungan rumah yang bisa ditentukan dengan menggunakan persamaan kuadrat yaitu:

$$
y=a x^{2}
$$

Pada rumah adat Toraja dibagian atap memiliki ciri khas yaitu lengkungannya. Dan lengkungan tersebut pada setiap rumah berbeda-beda, seperti pada Gambar 8
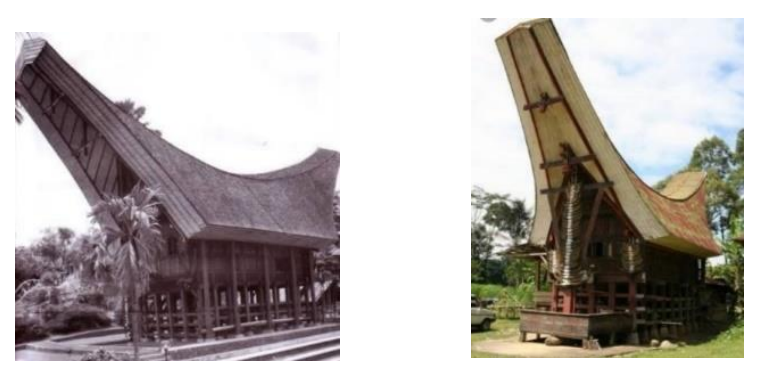

GAMBAR 8. Gambar (a) dan (b) adalah rumah adat toraja yang memiliki lengkungan yang berbeda 
Lengkungan tersebut bisa dibuat dengan memasang tiang atau rusuk pembentuk lengkungan disepanjang atap dari depan sampai belakang, seperti pada Gambar 9

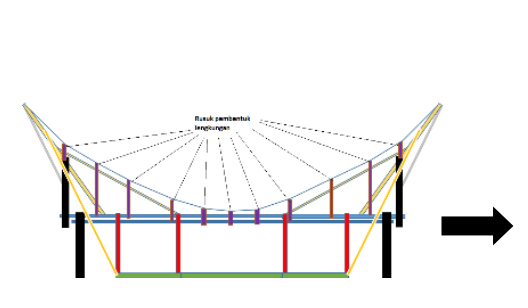

(a)

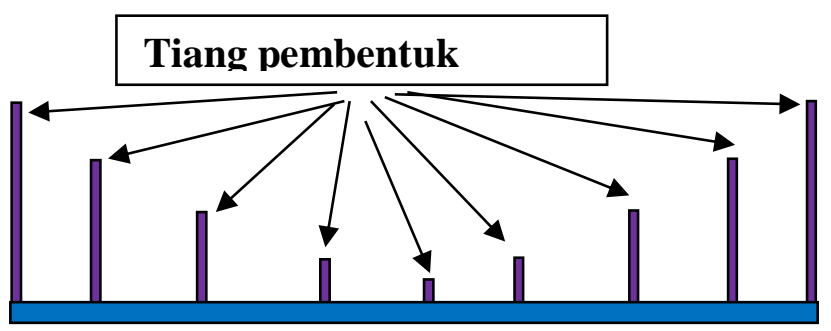

(b)

GAMBAR 9. (a)Sketsa atap rumah yang dilihat dari samping (b) Bagian rusuk atau tiang rumah yang disusun sehingga membentuk lengkungan.

Dengan adanya tiang tersebut lengkungan atap bisa dibentuk. Agar bisa meletakkan tiang pembentuk lengkungan dengan tepat dan dapat menghasilkan lengkungan yang sempurna maka bisa dengan menggunakan persamaan (2) agar bisa menentukan panjang setiap tiang pembentuk lengkungan dan jarak letaknya. Namun terlebih dahulu, adapun cara penentuan bentuk umum persamaan kurva atap rumah adat Toraja adalah dengan mengetahui bahwa ketika Gambar 9 bagian (b) digambar pada garis bilangan dengan sumbu x dan y, dimana titik $(0,0)$ terletak pada bagian tengah rumah, seperti pada Gambar 10.

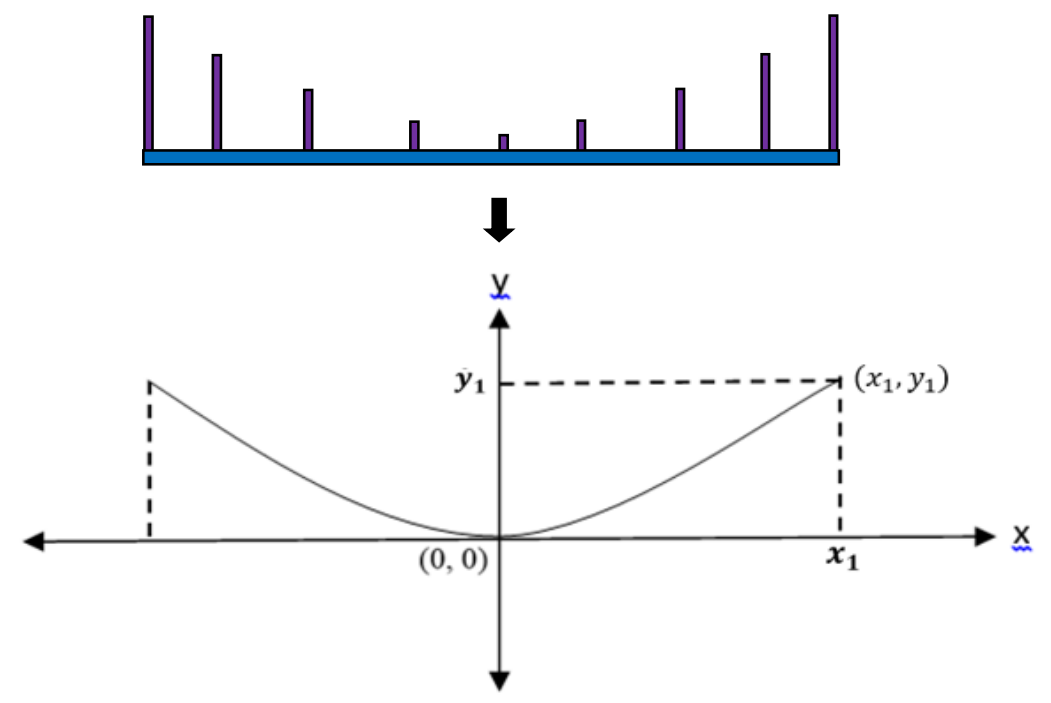

GAMBAR 10. Grafik fungsi pada lengkungan atap rumah

Terlihat $x_{1}$ adalah panjangnya rumah dari tengah sampai ujung depan dan $y_{1}$ adalah tinggi tiang atap paling luar. Sehingga nilai $x_{1}$ dan $y_{1}$ dapat diukur sebagai nilai awal untuk membentuk persamaan. Jika $(0,0)$ adalah titik puncak atau titik ekstrim dan $\left(x_{1}, y_{1}\right)$ adalah salah satu titik yang dilewati oleh kurva, serta dengan menggunakan bentuk umum persamaan kuadrat yaitu :

$$
y=a x^{2}+b x+c, a, b, c \in \boldsymbol{R}, a \neq 0
$$

maka persamaan umum kurva atap rumah Toraja bisa ditentukan. Ketika titik $(0,0)$ disubtitusi ke persamaan (3) maka diperoleh $c=0$ yang mengakibatkan persamaannya menjadi

$$
y=a x^{2}+b x
$$

Kemudian diketahui bahwa untuk menentukan suatu titik ekstrim bisa dengan cara menurunkan persamaan (4) dan hasil turunannya sama dengan 0

$$
y^{\prime}=2 a x+b=0
$$


Sehingga ketika nilai $x=0$ pada titik puncak disubtitusi ke persamaan (5) diperoleh $b=0$. Kemudian $b=0$ dan $c=0$ disubtitusi kembali pada persamaan umum (2) sehingga diperoleh kurva bentuk umumnya yaitu:

$$
y=a x^{2}, \text { dengan titik ekstrim }(0,0), \text { a positif dan } a \in \boldsymbol{R}
$$

Dengan adanya persamaan (2) kita bisa menentukan jarak setiap benteng pembentuk lengkungan dengan tepat dan seimbang.

Untuk memperjelas diberikan contoh kasus dimana diketahui panjang rumah sama dengan $8 \mathrm{~m}$ dan tinggi tiang atap terluar adalah 2 meter, terlihat seperti pada Gambar 11

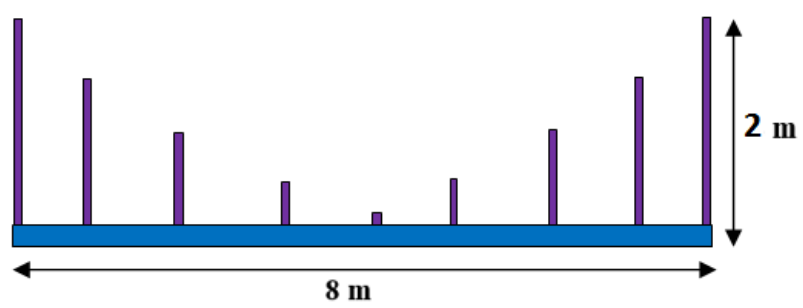

GAMBAR 11. panjang rumah dan tinggi atap

maka cara penentuan jarak setiap tiang pembentuk lengkungan adalah sebagai berikut:

Dik : $x_{1}=\frac{1}{2}$. panjang rumah $=4, y_{1}=2$

Dit : persamaan lengkungan atau kurva $=\ldots$ ?

$$
y=a x^{2} \quad \text {, dengan titik ekstrim }(0,0), \text { a positif dan } a \in \boldsymbol{R}
$$

Subtitusi nilai $x_{1}=4$ dan $y_{1}=2$ kedalam persamaan sehingga diperoleh:

$$
\begin{aligned}
& 2=a 4^{2} \\
& 2=a 16 \\
& a=\frac{2}{16} \\
& a=\frac{1}{8}
\end{aligned}
$$

kemudian subtitusi nilai $a$ kepersamaan (2) sehingga diperoleh persamaan lengkungan atap rumah adalah

Sehingga diperoleh,

$$
y=\frac{1}{8} x^{2}
$$

TABEL 1. Hasil fungsi $y=\frac{1}{8} x^{2}$ terhadap $x$

\begin{tabular}{ccc}
\hline $\begin{array}{c}\boldsymbol{x} \\
\text { (Satuan Meter) }\end{array}$ & $\begin{array}{c}\boldsymbol{y}=\frac{\mathbf{1}}{\mathbf{8}} \boldsymbol{x}^{\mathbf{2}} \\
(\text { Satuan Meter })\end{array}$ & $\begin{array}{c}\boldsymbol{y}=\frac{\mathbf{1}}{\mathbf{8}} \boldsymbol{x}^{\mathbf{2}} \\
\text { (Satuan Sentimeter })\end{array}$ \\
\hline-4 & 2 & 200 \\
-3 & 1,125 & 112,5 \\
-2 & 0,5 & 50 \\
-1 & 0,125 & 12,5 \\
0 & 0 & 0 \\
1 & 0,125 & 12,5 \\
2 & 0,5 & 50 \\
3 & 1,125 & 112,5 \\
4 & 2 & 200 \\
\hline
\end{tabular}


Dari Tabel 1 menunjukkan bahwa $x$ adalah jarak dari titik tengah rumah yaitu $(0,0)$ kesuatu titik tertentu. Sedangkan $y$ adalah tinggi balok pembentuk lengkungan yang diperoleh dari fungsi $y=$ $\frac{1}{8} x^{2}$. Untuk lebih jelasnya perhatikan Gambar 12 .

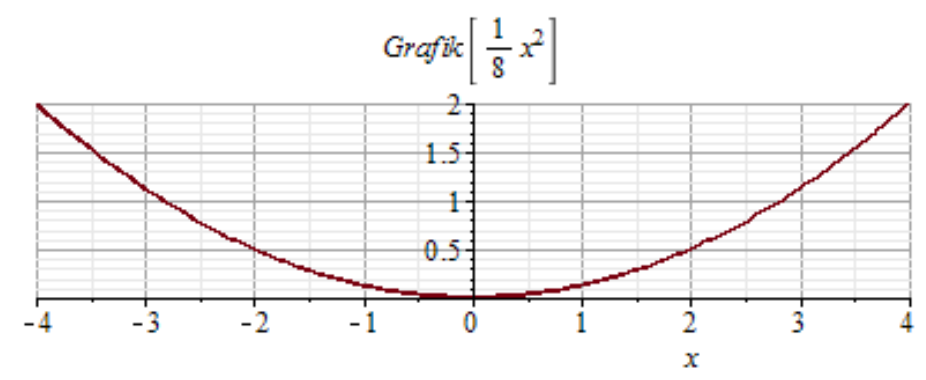

GAMBAR 12. Grafik penentuan lengkungan atap rumah panggung TorajA Jika digambarkan dalam bentuk keseluruhan maka ilustrasi gambarnya sebagai berikut:

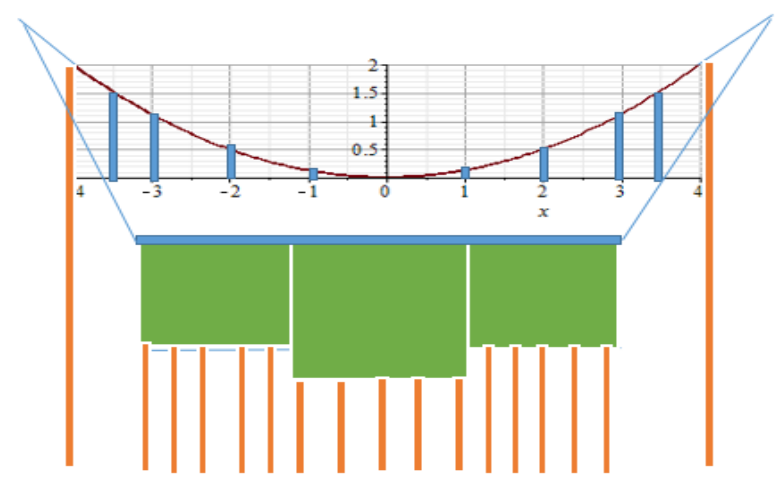

GAMBAR 13. Sketsa rangkap atap rumah dengan balok pembentuklengkungan yang sudah ditentukan dengan fungsi $\mathrm{y}=\frac{1}{8} \mathrm{x}^{2}$

\section{PEMBAHASAN}

Penelitian analisis matematika geometri terhadap rumah panggung toraja sebelumnya dilakukan oleh Pitriana (2015). Membahas tentang eksplorasi geometri budaya toraja dan menganalisis tentang geometri terhadap ukiran-ukiran yang terdapat dirumah adat Toraja. Pada penelitan ini dibahas tentang bagaimana hasil analisis dan penerapan matematika khususnya geometri pada pembuatan rumah panggung Toraja.

Hasil analisis matematika pada pembuatan rumah panggung Toraja didapatkan adanya penggunaan rumus sederhana dalam penentuan panjang rumah yaitu dengan menggunakan rumus $p=2 . l+1$ dimana $p$ adalah panjang rumah dan $l$ adalah lebar rumah. Selain itu diperoleh penggunaan hubungan dua titik menjadi ruas garis, kemudian menyeimbangkan lengkungan atap rumah dengan menggunakan sistem pencerminan dimana bagian tengah rumah yang menjadi sumbuh cerminan.

Penerapan matematika pada pembuatan rumah panggung Toraja adalah penggunaan persamaan kuadarat yaitu $y=a x^{2}$, dimana $x$ merupakan jarak antara titik tengah ketitik tertentu, $y$ merupakan tinggi balok pembentuk lengkungan dan $a$ adalah bilangan positif pada penentuans jarak tiang lengkungan agar dapat menghasilkan lengkungan yang tepat dan seimbang. Adapun manfaat ketika proses penentuan lengkungan rumah ini di sosialisasikan kemasyarakat pembuat rumah panggung Toraja adalah masyarakat Toraja bisa menentukan sendiri letak balok pembentuk lengkungan dengan teratur dan menentukan tingginya dengan menggunakan fungsi $y=a x^{2}$, dimana $x$ merupakan jarak antara titik tengah ketitik tertentu, $y$ merupakan tinggi balok 
pembentuk lengkungan dan $a$ adalah bilangan positif. Jadi masyarakat Toraja dalam membuat rumah panggung tidak susah lagi mengukur dan menggunakan tali untuk membentuk lengkungan rumah karena bisa langsung ditentukan dengan jarak yang diinginkan.

\section{KESIMPULAN}

Hasil analisis matematika terhadap pembuatan rumah panggung yaitu (1) barisan geometri pada jumlah setiap balok atau benteng rumah (2) penggunaan rumus pada penentuan panjang rumah (3) penerapan berat dan tekanan dalam penyusunan rangka rumah (4) penggunaan sistem hubungan dua titik dan perpanjangan garis dalam mengukur kemiringan rangka depan atap dan belakang (5) lengkungan pada atap rumah (6) kesebangunan dan kekongruengan pada bagian depan dan belakang rumah. Penerapan matematika pada pembuatan rumah panggung Toraja adalah penggunaan persamaan kuadarat yaitu $y=a x^{2}$, dimana $x$ merupakan jarak antara titik tengah ketitik tertentu, $y$ merupakan tinggi balok pembentuk lengkungan dan $a$ adalah bilangan positif pada penentuans jarak tiang lengkungan agar dapat menghasilkan lengkungan yang tepat dan seimbang

Dalam penelitian ini diharapkan adanya pengembangan lanjutan terhadap bagian-bagian rumah Toraja yang lain dan melakukan analisis matematika pada jenis rumah adat lainnya yang ada di Sulawesi Selatan atau yang ada diseluruh Indonesia.

\section{DAFTAR PUSTAKA}

Anisa, R. (5 Oktober 2017). Pengertian Geometri dan unsur-unsur Geometri. http:// ridhoanisa. Blogspot.com/2016/05/pengertian-geometri-dan-unsur-unsur.html. diakses pada tanggal 21 september 2018

Arafuru.(22 Juni 2014). 7 kelebihan rumah panggung. arafuru.com / lifestyle / inilah-7kelebihan-rumah panggung.html. diakses pada tanggal 15 Juni 2018

James. (1976), Pengertian Matematika Menurut Para Ahli. http: // www. Guru pendidikan.co.id/17-pengertian-matematika-menurut-para-ahli-beserta-bidangnya/. diakses pada tanggal 19 April 2018

Jannah, M.H. (28 Maret 2014). Peranan Ilmu Geometri dalam kehidupan, http://inventor95.blogspot.com/2015/03/peranan-ilmu-geometri-dalam-kehidupan.html. diakses pada tanggal 10 Juli 2018

Maspamuji, A. (8 Agustus 2016). Keunikan rumah tongkonan, rumah adat di indonesia. https:// www. Kompasiana. Com/ adiadiadi/ 573a7ddb44afbd10098d0694. diakses pada tanggal 3 Ferbruari 2019

Orey, D.C. (2000). The ethnomathematics of the Sioux tipi and cone. In H. Selin (Ed.), Mathematics across culture: the History of non- western mathematics (pp.239-252). Dordrecht, Netherlands: Kulwer Academic Publishers.

Ratnasari, N. (6 Maret 2016). Pengaplikasian Bangun Ruang pada Arsitektur Bangunan. http: // nirablogger. blogspot.com/2016/01/pengaplikasian- bangun-ruang.html. diakses pada tanggal 9 Juli 2018

Roro, F. (24 Agustus 2015). Pengertian rumah panggung sulawesi selatan. http://dediniblog .com/2015/11/rumah panggung .html. diakses pada tanggal 9 Juli 2018

Spradley, P. J.(2007). Metode Etnografi. Yogyakarta: Tiara Wacana.

Tandililing, P. (2015). Etbomatika Toraja (Eksplorasi Geometris Budaya Toraja. Jurnal Ilmiah Matematika dan Pembelajaran. 1(1).47-57 